\title{
PRÁTICA DA VELA: A QUESTÃo DOS RITOS E RISCOS
}

\author{
Emília Amélia Pinto Costa Rodrigues \\ Universidade Federal de Pernambuco, Pernambuco, Recife, Brasil \\ Priscilla Pinto Costa da Silva \\ Universidade Federal do Rio Grande do Norte, Rio Grande do Norte, Natal, Brasil \\ Patricia de Jesus Costa dos Santos \\ Universidade Federal de Campina Grande, Campina Grande, Paraíba, Brasil \\ Ana Raquel Mendes dos Santos \\ Universidade de Pernambuco, Pernambuco, Recife, Brasil \\ Bruno Medeiros Roldão de Araújo \\ Universidade Federal de Campina Grande, Campina Grande, Paraíba, Brasil \\ Clara Maria Silvestre Monteiro de Freitas \\ Universidade de Pernambuco, Pernambuco, Recife, Brasil
}

\begin{abstract}
Resumo
O estudo objetivou compreender o significado do rito na dimensão simbólica da prática da vela. A pesquisa etnográfica multisituada teve a participação de 19 velejadores da cidade de João Pessoa (Paraíba-Brasil), que foram entrevistados e observados antes, durante e após o velejo. Os resultados revelaram que os ritos na prática da vela consistem em três fases: i) passagem da terra para o mar, que caracteriza o afastamento da estrutura social; ii) fase limiar, a ação de velejar, que alcança o estado de comunhão; iii) passagem do mar para a terra, o reingresso à estrutura social, com a sensação de novo status. Conclui-se que os ritos na prática da vela colaboram para o velejador perceber a ressignificação da sua existência no mundo.
\end{abstract}

Palavras-chave: Rito. Riscos. Vela.

\section{PRACTICE OF SAILING: THE QUESTION OF RITES AND RISKS}

\begin{abstract}
The study aimed to understand the meaning of the rite in the symbolic dimension of the practice of sailing. The research, multi-sited and ethnographic, was attended by 19 sailors from João Pessoa (Paraíba, Brazi)l, who were interviewed and observed before, during and after sailing. The results revealed that the rites in the sailing practice consist in three phases: i) transition from land to sea, which features the detachment of the social structure, ii) threshold phase, the action of sailing reaching the state of communion, iii) transition from sea to land, reentering in the social structure with a new sense of status. It was concluded that the sailing rites collaborate in order to make the sailor realize the new meaning of his existence in the world.
\end{abstract}

Keywords: Ritual. Risks. Sailing. 


\section{PRÁCTICA DE VELA: UNA CUESTIÓN DE LOS RITOS Y RIESGOS}

\section{Resumen}

El estudio tuvo como objetivo comprender el significado del rito en la dimensión simbólica de la práctica de la vela. La investigación etnográfica multisituada, tuve participación de 19 practicantes de vela de la ciudad de João Pessoa, Paraíba, Brasil, donde fueran entrevistados y observados antes, durante y después de navegar. Los resultados revelaron que los ritos en la práctica de vela se consiste de tres fases: i) la transición de la tierra para el mar, que caracteriza el apartado de la estructura social; ii) fase inicial, la acción de practicar la vela, que alcanza el estado de comunión; iii) pasaje del mar para la tierra, el reingreso en la estructura social, con la sensación de nuevo status. Se concluye que los ritos en la práctica de vela colaboran para que el practicante vela percebe el resignificado de su existencia en el mundo.

Palabras clave: Rito. Riesgos. Vela.

\section{Introdução}

A necessidade de conhecer novos lugares e transportar pessoas e mercadorias se tornou possível por meio do barco à vela, o qual utiliza a força do vento sobre a vela para a realização do deslocamento do barco na água. A sua prática é reconhecida como uma atividade secular, de longa tradição em todo o mundo (DABOV; BERC, 2013), que envolve aspectos sociais, econômicos, culturais (BYRNES et al., 2016) e esportivos (TAN et al., 2016), sendo estes últimos para fins competitivos ou como atividades no contexto do lazer, as quais estão inseridas neste estudo como práticas corporais na natureza.

No Brasil, a discussão no campo científico sobre as práticas corporais na natureza teve início com as autoras Bruhns e Costa em meados da década de 1990, apresentando as dimensões simbólicas e representações sociais que se constituem nestas práticas. Bruhns (2009) ressalta o crescimento das práticas corporais na natureza desde a década de 1970, em que começaram a se expandir estas práticas em decorrência do contato com a natureza, melhorias nos equipamentos de segurança e da busca por diferentes sensações. Costa (1999) frisa que há uma insatisfação com o cotidiano dos seres humanos citadinos, tendo a necessidade de explorar as incertezas na natureza.

Em seguida, autores como Inácio et al. (2005a; 2005b), Schwartz (2006), Marinho (2008) e Bruhns (2009) evidenciam a importância dessa interação, apresentando o compromisso de mudanças de valores e atitudes, podendo desenvolver um comportamento ético e sensibilizador, além do reconhecimento do ser humano como elemento da natureza. Diante deste cenário, o ser humano vem procurando emoções vivenciáveis por meio destas práticas, as quais vêm ganhando anualmente novos adeptos como uma alternativa de lazer.

Neste sentido, o prazer nas práticas corporais na natureza está associado ao risco real e imaginário, como ressaltam os estudos de Marinho (2008, 2009) e Silva e Freitas (2010). O risco real é caracterizado pela assunção de uma situação em que há um aspecto negativo, envolvendo o risco de acidentes, lesões, doenças e até mesmo casos fatais; logo o risco imaginário é tratado sob a dimensão do calculado, sendo ancorado nos recursos tecnológicos. O risco nas práticas corporais na natureza pode ser compreendido, como indica Spink $(2001,2008)$, por risco-aventura, que compreende desafios no contexto da aventura na natureza.

Nesta multiplicidade, a busca do prazer, por meio do risco nas práticas corporais na natureza, constrói formas culturais e sociais de conjurar o perigo, como aponta Le Breton (2009). Desta forma, o autor apresenta que tais perigos podem ser afastados a partir de rituais que fortalecem de alguma forma o vínculo social. Os rituais de passagem envolvem o simbo- 
lismo, favorecendo a relação social e o "sentimento de estar garantido", como se fosse um último recurso que o praticante dá a si (LE BRETON, 2009, p. 85). A busca pelos rituais tem o sentido de garantir alguma segurança em relação às forças naturais, um controle além do que as técnicas racionais podem oferecer. Neste sentido, as formas de buscar os rituais favorecem o comportamento do ser humano, pois permitem promover uma relação com os elementos naturais, o que contribui para uma aproximação do ser humano com a natureza.

Le Breton (2009) apresenta os ritos ordálicos ou rito de passagem. Os ritos ordálicos buscam a justiça de Deus ou dos deuses para legitimar os assuntos dos seres humanos, tornando-se um rito oracular, que possui um valor pessoal (LE BRETON, 2009). O ser humano que se coloca em situação de risco está "em um intercâmbio simbólico com a morte", oferecendo a vida ao risco da morte. Em contrapartida, a expectativa é sair da situação de risco, exaltando a existência a partir da superação (LE BREETON, 2009, p. 79).

Pensando na sociedade pós-moderna, Giddens (1991) apresenta o risco como elemento intrínseco à conduta humana. Nesta perspectiva, o risco, seja real ou imaginário, em um contexto sociocultural à luz das práticas corporais na natureza apresenta contradições e conciliações entre os meios racionais e não-racionais (PIMENTEL, 2008). Sob a concepção do autor, a sociedade conservadora, quando se encontrava diante do risco, recorria aos ritos para proteção contra as ameaças advindas da natureza.

As práticas corporais na natureza apresentam uma conexão na dimensão simbólica ritual com a efetividade prática dos ritos em relação ao corpo e à sociabilidade na gestão dos riscos. A percepção dos riscos apontada por Pimentel (2010) está relacionada a uma racionalidade, que dialoga com os contextos de solidariedade do grupo e também com a intuição. $\mathrm{O}$ autor ressaltou que o praticante torna-se contraditório ao incorporar a experiência associando a técnica da prática à tecnologia voltada à percepção dos riscos.

O fato da utilização dos ritos, como lembra Cazeneuve [1985?], representa uma ação seguida de consequências reais, podendo ser uma condição de linguagem ou algo que se sobrepõe a consequências reais. Para compreensão mais acurada, o autor apresenta uma palavra de origem latina, os "ritus", que marcava as cerimônias, crenças sobrenaturais e até mesmo hábitos simples como os usos e costumes, formas de agir reproduzidas com certa invariabilidade. Neste entendimento, o rito é uma ação marcada pelo comportamento estereotipado, considerando que este evolui com o passar do tempo, portanto é imperceptível (CAZENEUVE, [1985?]).

Contudo, o autor supracitado completa seu pensamento frisando que o rito pode sofrer o risco de perder seu valor e sua razão caso ocorra uma modificação brusca. Portanto, o rito é uma ação em que a eficácia pode ser real ou pretendida, e não acaba na união empírica das causas e efeitos. Em conformidade com este raciocínio, a magia representacional, realizada a partir de um rito, torna-o simbolicamente eficaz. Nos estudos de Pimentel (2008), os rituais indicam que há uma ideia alternativa da estrutura social, remetida a uma composição diacrônica do rito, havendo um afastamento do cotidiano por um momento, e um retorno mais tarde, à realidade social, formando uma tríade "separação-margem-reagregação".

$\mathrm{Na}$ mesma linha de raciocínio, estes processos recaem nos ritos de passagem, conforme Turner (1974) e Van Gannep (1978), entendendo como passagem um acontecimento que se coloca entre duas situações. À luz da concepção dos autores, os ritos de passagem são classificados em três fases: pré-liminar, liminar e pós-liminar.

Assim, o ritual de passagem apresenta a fase pré-liminar como um distanciamento do sujeito da estrutura social. A liminaridade é a fase intermediária, que se caracteriza por esse distanciamento e reaproximação do indivíduo. Assim, o indivíduo, em um estado liminar, encontra-se fora da estrutura social normal, tornando intermediárias as estruturas que conduziram o passado e as que buscam conduzir o futuro (TURNER, 1974). Na argumentação do autor, outra estrutura que os ritos de passagem desempenham é o estado conhecido por 
"communitas", que exerce a função de equilibrar a estrutura, que se refere à igualdade entre as pessoas, na perspectiva cultural antropológica. A fase pós-liminar consiste no retorno à estrutura social, apresentando um novo status. Neste sentido, Rodrigues et al. (2009) dedicaram seus estudos aos alpinistas e revelaram que, por meio desta prática, os escaladores mostraram mais orientação para o seu ego.

Diante deste cenário, Turner (1974) declara que durante este estágio de transição, que está aberto às mudanças, a passagem pode ser ritualizada de várias maneiras, no entanto, 0 que é marcante é a presença de símbolos, que podem representar desde o nascimento até a morte. Para Eliade (2008; 2011), os símbolos podem se comunicar com o sagrado e esta relação constitui a imagem exemplar da transcendência que é inspirada e alimentada por numerosos rituais. Neste momento os corpos se comportam de forma ambígua, na qual o "talvez", o "pode ser", a "hipótese" são marcantes nesta fase, despertando para novas transformações, trazendo um rol de possibilidades; assim, neste fazer a realidade é transformada em possibilidades (TURNER, 1974).

Perante os ritos, a situação ou a ameaça dos riscos, o corpo transmite uma linguagem bem diferente da fala, mas, nesse tocante, a linguagem corporal do ser humano apresenta características particulares, quer seja um gesto, um sorriso, a forma de andar, uma expressão (MORRIS, 1996). Analisados de forma conjunta, o autor expõe que os sinais são realizados inconscientemente à medida que se fala, e auxiliam nas palavras, transmitindo as mudanças de humor e caracterizando o estado emocional, como se fossem uma forma de subtexto que conduz a um sistema de conversação.

A partir dessa caracterização, a prática da vela é percebida como uma linguagem corporal, na qual o corpo que veleja emite sinais e símbolos peculiares desta prática quando está na preparação dos ritos de passagem, velejando ou em situação de risco. Nesse olhar, o corpo é capaz de comunicar multiplicidades de gestos e sinais aptos a transmitir mensagens que tornam possível o entendimento por meio expressivo. Desta forma, o estudo tem como objetivo compreender o significado do rito na dimensão simbólica da prática da vela.

\section{Procedimentos Metodológicos}

O presente estudo caracteriza-se como uma pesquisa etnográfica multisituada (MARCUS, 1995), por explorar analiticamente processos envolvendo dois ou mais lugares e suas interconexões que formam composição etnográfica centradas em diferentes locais, enfatizando o entendimento e valores dos conhecimentos parciais. Desta forma, a pesquisa etnográfica multisituada permite compreender informações sobre dimensões micro e macro da dialética cultural, uma vez que concede ao pesquisador buscar populações, ideias e objetos por meio do tempo e do espaço.

O grupo selecionado para o desenvolvimento da pesquisa foi formado por 19 velejadores da cidade de João Pessoa (Paraíba - Brasil), associados ao Iate Clube da Paraíba, os quais praticam a vela há pelo menos cinco anos. Os instrumentos utilizados para coletar os dados foram o roteiro de entrevista semiestruturada e o de observação. Como recursos para registro das informações foi organizado um diário de campo, e foram utilizadas duas câmeras digitais, que auxiliaram na coleta dos dados no Iate Clube da Paraíba e na Praia do Bessa/PB. Os registros imagéticos foram realizados nos momentos das montagens do barco à vela, na transição da terra para a água, na fase de velejo, na transição da água para a terra e na desmontagem da embarcação. As entrevistas foram transcritas e apreciadas juntamente com os dados visuais e estudadas à luz da análise de conteúdo de Bardin (2009).

Foram respeitados os aspectos éticos da pesquisa. Todos os atores sociais participantes da pesquisa assinaram o Termo de Consentimento Livre e Esclarecido. 


\section{Resultados e Discussão}

\section{Os ritos na prática da vela}

A escolha do barco à vela envolve apreciações peculiares, podendo haver um ou vários tripulantes, como aponta Schmidt (1979), destacando-se que para a seleção do barco é importante ressaltar os fatores de ordem pessoal, como gasto, tempo disponível, tamanho da extensão da água disponível, e ainda é preciso acrescentar as características físicas e fisiológicas do praticante. Dentre os diversos tipos de embarcações à vela, nos quais se destacam as classes Laser, Star, Finn, Optmist, Europa, 470, 49'er, Tornado, Dingue, Hobie Cat, é possível observar características semelhantes no que diz respeito aos ritos que envolvem a prática da vela, sem destacar a classe à qual a embarcação pertence.

Ainda seguindo as ideias de Schmidt (1979), para a realização da prática da vela é preciso verificar as condições meteorológicas e checar os equipamentos necessários. Para tanto, é necessário que o velejador tenha experiências sensoriais, sendo capaz de observar a direção e a força do vento, as condições do mar na saída e a prevenção de como estará o local na chegada, devido à mudança da maré com o tempo. Também, é necessário observar a influência da fase da lua nos ciclos da maré e conferir o material minuciosamente, observando as condições de uso de cada peça da embarcação. Quanto a este aspecto, é importante ressaltar o respeito e as individualidades de cada elemento, verificando a segurança, para minimizar possíveis eventualidades ao percorrer três estágios interligados ao risco, os quais são a saída para o mar, o velejo e a volta para a terra, seguindo as fases propostas nos estudos de Turner (1974). Como apresenta Turner (1974), que acompanha uma passagem pelos limites, o presente estudo analisa os ritos de passagem que consistem na transição do ambiente terrestre para o aquático, o ambiente aquático e, por fim, o retorno a terra. Na prática da vela, o velejador necessita observar e organizar todos esses aspectos, em decorrência dos ritos que conduzem estes ao mar e trazem de volta a terra.

Como no voo livre, estudado por Pimentel (2008), os ritos de passagem na prática da vela também podem se caracterizar a partir de duas concepções, em que a primeira se refere à tríade separação-margem-reagregação, que diz respeito ao afastamento do velejador da estrutura social, introduzindo-o a uma nova sociedade, e em seguida, retornando à estrutura social. A segunda concepção trata da relação do espaço e do tempo, em que a ação de velejar afasta o velejador do cotidiano e o insere na dimensão liminar, retornando, depois, a terra. Essa ambiguidade de concepções faz referência aos ritos que permitem, por um ângulo, a integração social e, por outro, o espaço e tempo na busca de superar receios, além da percepção do sentido de uma nova vivência, quebrando paradigmas de status, no sentido simbólico, entre os praticantes. Neste sentido, foram estabelecidas categorias analíticas, as quais conduziram a três momentos, apresentados a seguir.

\section{Em direção ao mar: os ritos de entrada}

A transição na prática da vela sucede da passagem da terra para o mar, o qual é visto como um ambiente imprevisível. Le Breton (2007, p. 12) apresenta o mar como "[...] uma reserva selvagem de sentidos, um mundo, ao mesmo tempo, propício e perigoso onde o homem, se estiver à altura, demonstra justamente sua legitimidade e sua jubilação em existir". Para os ritos de entrada, os velejadores observam e se preparam em diversos aspectos, tanto nos físicos e psicológicos, como nos ambientais e climáticos.

A preparação física dos atores sociais envolvidos nesse estudo se consistiu de alongamentos e treinamentos aeróbios e anaeróbios, como declarou o entrevistado 3: “[...] eu faço um trabalho de musculação e um trabalho aeróbico, com ciclismo e corrida". Neste momento 
é importante trazer os estudos de Vasconcelos-Raposo et al. (2007), que apontam, para o período pré-competitivo, a preparação específica em âmbito físico e psíquico. Além do preparo físico, declarado pelo entrevistado, no que diz respeito aos aspectos psicológicos, também foram destacadas a ansiedade e a preparação reflexiva entre o "eu-sujeito" e a natureza, como indica o entrevistado 7 informando: "[...] fazer um pouco de reflexão e um respeito extremo com o fator ambiental externo, que é a natureza".

Nessa direção, Lavoura (2007) contribui no que recai nos aspectos da ansiedade e do medo, relatando que os níveis emocionais podem afetar o comportamento dos praticantes negativamente. Seguindo ainda essa mesma linha de pensamento, vale destacar o estudo de Fernandes, Bombas e Lázaro (2007), os quais ressaltam a importância dos fatores psicólogos, que recaem na preparação psíquica. Outros estudos investigaram o estresse psicológico dos velejadores e revelaram a importância de os praticantes conseguirem controlar os elevados níveis de estresse psicológicos (SEGATO et al. 2010).

No que referem aos aspectos ambientais e climáticos, os velejadores apresentaram um rol de fatores que são de importância singular para verificar as condições climáticas do velejo, como força e direção do vento e a tábua da maré, ressaltando a fase preparatória para o velejo ainda em suas residências, como declara o entrevistado 18: "[...] em casa, antes mesmo, eu já estou pensando qual peça da embarcação que faz tempo que eu não troco".

$\mathrm{O}$ entrevistado de número 5 apontou a meteorologia como um fator determinante na prática da vela, estimulado os praticantes a procurarem informações disponíveis em vários sites, de fácil e livre acesso ao público, indicando a hora do nível mais alto e mais baixo da maré, assim como a força e a direção do vento nas diversas regiões com antecedência de 5 dias. Além do auxílio tecnológico, os velejadores percebem alguns sinais transmitidos pela natureza, tais como a direção e força do vento, a influência da lua na tábua da maré e as condições climáticas ao olhar o céu.

Estes elementos, por meio das observações, despertaram para a relação ser humanonatureza, possibilitando uma aproximação e inserção no cosmo. Autores como Brunhs (2009), Marinho (2008, 2009) e Marinho e Inácio (2007) descreveram os fatores naturais e a relação do ser humano, destacando uma correspondência entre eles, desta forma, a prática da vela contribui para a integração e a intercomunicação entre o eu-sujeito e os elementos naturais. Para tal compreensão, Bruhns (2009) informa que não são nas primeiras vivências que essa aproximação e integração com a natureza se concretizam, portanto são necessárias várias experiências para despertar a relação. Partindo destas análises, alguns entrevistados, como os de números 6 e 13, relataram que, a partir das vivências com a prática da vela os velejadores vão adquirindo mais experiências, tanto no que refere aos aspectos ambientais e climáticos, quanto no que recai nos conhecimentos técnicos da prática da vela e da embarcação.

Cabe realçar que a montagem dos barcos requer atenção aos detalhes nas condições e encaixes das peças e dos nós. As filmagens da montagem da embarcação foram realizadas pelos próprios velejadores, sendo, algumas vezes, essa montagem revisada por um marinheiro, na tentativa de minimizar possíveis erros. Após a montagem do barco, ainda são analisadas pelos velejadores as condições climáticas, o mar (o nível da maré e intensidade das ondas), o céu (se está claro ou com possibilidades de chuvas intensas) e o vento (a direção e a força), que altera significativamente sua intensidade. Cita-se, como exemplo, um velejador de windsurf que, durante as filmagens, ao terminar a montagem da prancha à vela, se preparava para a entrada no mar, quando o vento mudou rapidamente de intensidade, acarretando a não passagem para o mar, e o velejador explicou que o vento diminui a força, ficando insuficiente para velejar.

Ao completar este primeiro momento da pré-verificação climática, a montagem de barco e preparação do velejador são o momento da passagem da terra para o mar, tendo em 
frente as ondas e seus significados simbólicos, como declaram Chevalier e Cheerbrant (1994, p. 658-659):

[...] as ondas fazem e desfazem incessantemente com seus líquidos bordados ao som de música sonora e grave. Simbolizam o princípio passivo, que se deixa levar; mas elas se erguem com outra força, perigosa, representando toda a força da profunda inércia. Simbolizam as súbitas irrupções do inconsciente, massa de inércia enganadora, impelida pelas pulsões instintivas a atacar o espírito, o ego dirigido pela razão.

De fato, o mar, como elemento incerto, indica a imponderabilidade da prática da vela, que traz nos ritos a segurança por meio das forças naturais. A passagem da terra para o mar, geralmente, é realizada com a ajuda do marinheiro, principalmente para as embarcações maiores, como o Hobie Cat, as quais são empurradas em uma espécie de carrinho de fabricação artesanal, de dentro do clube, onde são montadas as embarcações, até a praia, logo nas primeiras ondas, e de lá são empurradas para o mar.

Em síntese, a preparação da passagem da terra para o mar é antecedida por fatores que conduzem ao afastamento do velejador da estrutura social, o que se inicia desde os momentos das observações climáticas, de forma excêntrica do cotidiano. A busca pela segurança por meio das preparações técnicas e psicológicas, bem como a ambiguidade proporcionada pelo mar, ora transmitindo tranquilidade, ora transmitindo fúria, são signos interpretados pelos velejadores ainda em terra, os quais são considerados na preparação da prática da vela.

\section{Entrando no mar: os ritos do velejo}

Ao entrar no mar, em sua embarcação, o velejador encontra-se na fase liminar, em que Le Breton (2007) ressalta que o indivíduo fica suspenso em seu veleiro, entregue aos seus recursos. O autor aponta que o mar é uma via elevada de sentido reconquistado, em que o ser humano, com apenas os recursos físicos e morais, em circunstâncias escolhidas por ele mesmo, traz novas sensações e emoções, reencontrando a sua existência.

Diante desta perspectiva, na fase liminar o velejador se encontra em outra dimensão, por meio de dois sentidos, sendo o primeiro referente ao corpo que veleja e o segundo trata-se do afastamento efêmero das preocupações do cotidiano, como declara o entrevistado 8 ao relatar que "[...] quando eu entro em um barco eu me esqueço de tudo". O entrevistado 7 informa que se sente "[...] uma pessoa extremamente tranquila, zen, relaxada sem problema nenhum. É o êxtase, é uma coisa inexplicável".

Como adverte Le Breton (2007, p. 16), a vivência "[...] no mar afasta da ambivalência do mundo, das decepções que os outros, às vezes, provocam: ela reduz a existência cotidiana a uma série de gestos preciosos e libera o imaginário, a meditação". Nessa fase, o velejador se encontra no estado de communitas, pois o corpo parece estar mais sensível, despertando para informações sensoriais. Nesta fase a atenção é centrada no mar, na direção e intensidade do vento. O entrevistado 18 relata que o mar informa quando algo está errado ou por onde não se deve ir, "[...] quando encontramos ondas pequenas formando a espuminha branca, quer dizer que ali há pedras ou paredes de corais, que se bater pode danificar o barco".

Quando a embarcação exige uma tripulação, como exemplo as classes oceânicas, cada velejador tem a sua posição, como é caso do timoneiro, o qual é responsável pela direção da embarcação, e avisa à tripulação a hora de dar um bordo, ao girar a cana-de-leme. É importante destacar o momento do bordo, pois requer a atenção da tripulação para o movimento e troca da posição no veleiro. Segundo Schmidt (1979), este movimento consiste na proa atravessar a linha do vento, e as velas começarem a "panejar", mudando de lado, enchendo-se novamente com o vento, e o timoneiro volta à cana-de-leme, a posição do meio, tomando um novo rumo. 
Neste momento, a tripulação precisa ser bem integrada, pois a vida de cada um depende das ações e condutas do outro, em que cada velejador deve proteger a si mesmo e ao outro e não colocar "[...] a vida da tripulação em risco", como foi apontado pelo entrevistado 11. Neste sentido, a segurança é responsabilidade de toda a tripulação, sendo intercedida pelos ritos e pela permanente relação com os elementos naturais, os quais tentam tirar as vantagens (LE BRETON, 2007). Diante deste quadro analítico, Le Breton (2006, p. 99) aponta que "[...] tudo o que passa pelo corpo é valorizado", como a resistência, a força, o esforço pela sobrevivência. As sensações de prazer, como relataram os entrevistados, são uma característica marcante nesta fase, pois é um momento de descobertas e sensações corporais, sendo estas positivas e negativas, uma espécie de prazer por estar enfrentando o risco no mar, que se mistura à sensação de liberdade declarada pelos entrevistados. Le Breton (2007) explica que o barco é como uma bolha que se distancia do mundo, sem compromisso com a duração, sendo a navegação um momento de meditação e reflexão pessoal à luz do sentido da existência, considerando que a comunicação com a terra nunca é cortada e permanece interligada.

Nesse cenário, os rituais de transcendência podem ser percebidos como o distanciamento do profano para ingressar no sagrado, como ressalta Costa $(1999,2000)$ nos estudos sobre o montanhismo, frisando que quando o sujeito transcende do mundo profano, isso permite acender a uma condição espiritual superior, aproximando-se ao sagrado ao encontrar o tempo mítico, marcado como o tempo existencial. Sobre este aspecto, percebe-se uma analogia entre os estudos de Turner (1974) e Costa (1999), em que se permite mudar o estado de transcendência, seja na terra, no ar, ou no mar. Para Costa (1999, p. 55), essa transição é uma "[...] dialética da hierofania o profano se transforma em sagrado e a dessacralização transforma o sagrado em profano".

Em suma, a fase liminar apresenta uma forma própria para cada velejador, em que, por meio da vivência no mar, distante da estrutura social, revelam-se sensações e novos conhecimentos. Este distanciamento simbólico, nesse estágio, representa um estado de comunhão e igualdade, despertado na relação ser humano-natureza, reconhecendo um laço humano com o cosmo, laço esse que recai no fortalecimento da existência do praticante, sendo desprovido de status. A mudança provocada pela fase da liminaridade permite um reencontro do velejador consigo, uma renovação dos sentidos, revelando sua identidade.

\section{Saindo do mar: os ritos de reingresso}

A fase pós-liminar se refere ao momento de transição do velejador do mar para terra, a passagem do incerto para o reingresso à estrutura social, no que diz respeito à consciência e à transição de um modo de ser para outro, que foi modificado. Se o mar estava em fúria na fase liminar os velejadores são recebidos com maior prestígio, mas não desconsiderando a volta dos velejadores que encontraram o mar em sua calmaria. Neste sentido, Le Breton (2006) indica que a situação mais desprovida é vista como uma intensificação de reconhecimento no mundo.

Nesta direção, o reingresso pode ser provido de duas situações distintas, a primeira condiz com o momento em que o velejador percebe o período de voltar ou a falta de pretensão de continuar no mar; e a segunda pelo fato de algum imprevisto, como a quebra de equipamento ou a mudança brusca do clima, que impossibilita a continuação da prática, como ocorreu em uma das filmagens, após a saída de um torneio de Hobie Cat 14, quando uma das embarcações retornou, pela quebra de um dos cabos do veleiro. Em ambas as situações, todos se cumprimentaram e se confraternizaram de alguma forma, descrevendo o que encontraram e o que ocorreu nos momentos singulares, compartilhando com os amigos os conhecimentos adquiridos e as recordações expressadas por meio das emoções e sentimentos. 
Como aponta Le Breton (2006), esse grupo de amigos é reduzido aos que buscam alcançar os mesmos objetivos, passando pelos mesmos esforços, porém de forma solidária. Como declara o entrevistado 6 "[...] geralmente vai se encontrar com amigos, com a família... eu acredito que a volta a casa sempre é muito bom". Outro depoimento que é importante destacar, quanto a este aspecto, é o do participante 13, quando confessa que "[...] todo ser humano, por mais aventureiro, por mais do mar que goste, sempre tem sua âncora lançada em algum pontozinho na terra. Então, voltar pra nossa casa, pro aconchego da família, na terra também é bom, renovar as energias para voltarmos ao mar novamente".

Uma análise sobre o regresso a terra para os entrevistados pode ser categorizada a partir de dois polos de sensações, um positivo e o outro negativo. O positivo se refere às sensações de alegria, satisfação, realização, êxtase, renovação, euforia, fortalecimento, tranquilidade e alívio. O que diz respeito às sensações negativas são os sentimentos de tristeza, cansaço e saturação, mas após algum tempo em terra, volta uma certa ansiedade de voltar ao mar.

Como na fase pré-liminar, a passagem do mar para a terra também é realizada com apoio de um marinheiro, que transporta o veleiro até o clube. Ao retornar ao clube, todo o barco é higienizado, peça por peça, desmontado e guardado em um local apropriado. A desmontagem, geralmente, é realizada por um marinheiro, sendo considerada o final do velejo. Nesse momento, recorre-se a Le Breton (2006), que descreve o reingresso como um momento em que o velejador se reestrutura na sociedade, na busca do reencontro, dando sentido à existência humana.

No mundo simbólico, como ressaltam Chevalier e Gheerbrant (1994, p.141-144), a cor branca da embarcação representa a "[...] cor de passagem, dos ritos. Cor da partida para a morte, ligado ao fenômeno iniciático. Na acepção diurna, a cor da revelação, da graça, da transfiguração; é a cor da manifestação de Deus". O simbolismo nos ritos de passagem evoca a ideia de transação e transformação de um estado para o outro, como declara o entrevistado 13, que entende a volta a terra como uma renovação. O reingresso é uma forma de superar os obstáculos encontrados na fase liminar, como um fortalecimento para a travessia. Como afirma Le Breton (2009), é uma forma de conservar uma relação de sentidos entre o próprio ator social e o mundo.

Para sintetizar, os ritos de reingresso concebem símbolos representativos da morte para a vida, manifestando a epistemologia da existência. Os discursos parecem sedutores, pois tratam de uma forma de mediação de um mundo imaginário, particular e paradisíaco, em que as emoções dominam o espaço, para o mundo dos mortais, o qual não é capaz de despertar essas sensações de euforia. $O$ rito de transcendência representa uma ultrapassagem com segurança, do ambiente incerto para a terra, representando a volta de uma viagem de sacrifício, o retorno do sagrado para o profano. Essa transcendência, na argumentação de Le Breton (2007), representa um jogo simbólico com a morte, e vai ao encontro do sagrado, quando a morte é simbolicamente vencida, e o ser humano tem o direito de continuar no mundo dos mortais renascendo em nova legitimidade.

\section{Conclusão}

O estudo, por meio da pesquisa etnográfica multisituada, apresentou os ritos que envolvem a prática da vela, compreendendo seus significados na dimensão simbólica, envoltos na interpretação, nos signos e nos referentes que constituem a ação de velejar. Assim, foi discutida a percepção de velejar, bem como as sensações que esta prática desperta nas suas diferentes fases, a saída para o mar, a ação de velejar e a volta a terra. No que refere à passagem da terra para o mar foram destacadas as preparações técnica e psicológica; sobre o velejo, enfatizaram-se as emoções e sensações vivenciadas; referente ao reingresso, foi realçado o sentimento de euforia. 
No contexto para a compreensão dos ritos da prática da vela, a sua manifestação está associada aos gestos e símbolos que tendem a minimizar os riscos. No que se refere aos ritos de passagem, foram observados o distanciamento da estrutura social - ida ao mar, em que o ser humano se encontra em um estado de igualdade e comunhão; e o retorno a terra - voltando à realidade da estrutura social, no entanto, com um novo status, simbolicamente transformado. Portanto, os ritos na prática da vela consistem em uma mutação e ressignificação em si e na existência no mundo.

Para além destas considerações, é importante ampliar o estudo para outros olhares da prática da vela, visto que há limitações na presente pesquisa à luz dos ritos e riscos amparada na etnografia multisitual, na busca de ampliar os conhecimentos relacionados aos aspectos no contexto do lazer e suas influências no cotidiano.

\section{Referências}

BARDIN, L. Análise de conteúdo. Tradução L. A. Reto e A. Pinheiro. São Paulo: Edições 70, Livraria Martins, 2009.

BRUHNS, H. T. A busca pela natureza: turismo e aventura. Barueri: Manole, 2009.

BYRNES, T. et al. Environmental management of boating related impacts by comercial fishing, dailing, anddiving tour boat operators in Autralia. Journal of Cleaner Production, v. 111, n. 16, p. 383-398, 2016.

CAZENEUVE, J. Sociologia do rito. Porto: Editora Rés, [1985].

CHEVALIER, J, GHEERBRANT, A. Dicionário de símbolos. Rio de Janeiro: José Olympio, 1994.

COSTA, V. L. M. Esporte de aventura e risco na montanha: uma trajetória de jogo com limites e incerteza. Tese (Doutorado em Educação Física). Universidade Gama Filho, Rio de Janeiro, 1999.

COSTA, V. L. M. Esportes de aventura e risco na montanha. São Paulo: Manole, 2000.

DABOV, T.; BERC, G. Importance of participation of people with physical disabilities in sailing as a recreational activity. Hrvatska revija za rehabilitacijska istraživanja, Zagreb, v. 49, n. 1, jun. 2013.

ELIADE, M. Tratado de história das religiões. 3. ed. São Paulo: Martins Fontes, 2008.

ELIADE, M. O sagrado e o profano: a essência das religiões. 3. ed. São Paulo: WMF Martins Fontes, 2011.

FERNANDES, H. M.; BOMBAS, C.; LÁZARO, J. P. Perfil psicológico e sua importância no rendimento em vela. Motricidade, v. 3, n. 3, p. 24-32, 2007.

GIDDENS, A. As conseqüências da modernidade. São Paulo: Editora Unesp, 1991. 
INÁCIO, H. L. D.; SILVA, A. P. S.; PERETTI, E. LIESENFELD, P. A. Travessuras e Artes na Natureza: movimentos de uma sinfonia. In: SILVA, A. M.; DAMIANI, I. R. (Org.) Práticas corporais: experiências em Educação Física para a outra formação humana. Florianópolis: Nauemblu Ciência \& Arte, 2005a. v. 2.

. Bastidores das práticas de aventura na natureza. In: SILVA, A. M.; DAMIANI, I. Regina (Org.). Práticas corporais: experiências em Educação Física para a outra formação humana. Florianópolis: Nauemblu Ciência \& Arte, 2005b. v. 3.

LAVOURA, T. N. Estados emocionais: a investigação do medo no contexto esportivo. 2007. 388f. Dissertação (Mestrado em Pedagogia da motricidade humana) - Universidade Estadual Paulista, Rio Claro, 2007.

LE BRETON, D. Risco e lazer na natureza. In: MARINHO, A.; BRUHNS, H. T. (Org.). Viagens, lazer e esporte: o espaço da natureza. Barueri: Manole, 2006.

LE BRETON, D. Aqueles que vão para o mar: o risco e o mar. Revista Brasileira de Ciências do Esporte, Campinas, v. 28, n. 3, p. 9-19, maio 2007.

LE BRETON, D. Condutas de risco: dos jogos de morte ao jogo de viver. Tradução L. L. Oliveira. Campinas: Autores Associados, 2009.

MARCUS, G. E. Ethnography of the world-system: The emergence of multisited ethnography. Annual Review of Anthropology, v. 24, p. 95-117, out. 1995.

MARINHO, A.; INÁCIO, H. L. D. Educação física, meio ambiente e aventura: um percurso por vias instigantes. Revista Brasileira de Ciências do Esporte, Campinas, v. 28, n. 3, p. 5570, maio 2007.

MARINHO, A. Lazer, aventura e risco: reflexões sobre atividades realizadas na natureza. Movimento, Porto Alegre, v .14, n. 2, p.181-206, maio/ago. 2008.

MARINHO, A. Lazer, aventura e ficção: possibilidades para refletir sobre atividades realizadas na natureza. Motriz, Rio Claro, v. 15, n. 1, p. 1-12, jan./mar. 2009.

MORRIS, D. O Animal humano: uma perspectiva pessoal da espécie humana. Lisboa: Gradiva, 1996.

PIMENTEL, G. G. A. Ritos e risco na prática do vôo livre. Movimento, Porto Alegre, v. 14, n. 3, p. 13-32, set./dez. 2008.

Percepção dos riscos, condicionamento corporal e interações sociais no voo livre.

Revista Brasileira de Ciências do Esporte, Campinas, v. 31, n. 2, p. 45-59, jan. 2010.

RODRIGUES, A. D., LÁZARO, J. P., FERNANDES, H. M, VASCONCELOS-RAPOSO, J. Caracterização dos níveis de negativismo, activação, autoconfiança e orientações motivacionais de alpinistas. Motricidade, v. 5, n. 2, p. 63-86. 2009.

SCHMIDT, J. G. Aprenda a Velejar. Editora Tecnoprint, 1979. 
SCHWARTZ, G. M. A aventura no âmbito do lazer: as AFAN em foco. In: Aventuras na natureza: consolidando significados. Jundiaí: Fontoura Editora, 2006. (Org.).

SEGATO, L.; BRANDT, R.; LIZ, C. M.; VASCONCELLOS, D. I. C.; ANDRADE, A. Estresse psicológico de velejadores de alto nível esportivo em competição. Motricidade, v. 6, n. 3, p. 53-62, 2010.

SILVA P. P. C.; FREITAS, C. M. S. M. Emoções e riscos nas práticas corporais na natureza: uma revisão sistemática. Motriz, Rio Claro, v. 16, n. 1, p. 221-230, jan./mar. 2010.

SPINK, M. J. P. Trópicos do discurso sobre risco: risco-aventura como metáfora na modernidade tardia. Caderno Saúde Pública, Rio de Janeiro, v. 17, n. 6, p. 1277-1289, 2001.

Posicionando pessoas como aventureiros potenciais: imagens de risco-aventura em matérias de revista. Psicologia \& Sociedade [online], n. 20, p. 50-60, 2008.

TAN, B. et al. Injury and illness surveillance at the International Sailing Federation Sailing Word Championships 2014. British Journal of Sports Medicine, v. 50, n. 11, p. 673-681, 2016.

TURNER, V. O processo ritual: estrutura e antiestrutura. Petrópolis: Vozes, 1974.

VAN GENNEP, A. Os ritos de passagem. Petrópolis: Vozes, 1978.

VASCONCELOS-RAPOSO, J.; LÁZARO, J. P.; TEIXEIRA, C.; MOTA, M. P.; FERNANDES, H. M. Caracterização dos níveis de ansiedade em praticantes de atletismo: Níveis de Ansiedade no Atletismo. Motricidade, v. 3, n. 1, p. 298-314, 2007.

Recebido em: 03/02/2017

Revisado em: 29/05/2017

Aprovado em: 15/05/2018

Endereço para correspondência:

milapcosta@ hotmail.com

Emília Amélia Pinto Costa Rodrigues

Universidade de Pernambuco, Escola Superior de Educação Física.

Rua Arnóbio Marques 310 - Hospital Osvaldo Cruz

Boa Vista

50100901 - Recife, PE - Brasil 